\title{
Assessment of the influence of drift orientation on observed levels of squeezing in hard rock mines
}

\author{
J. Hadjigeorgiou Lassonde Institute of Mining, University of Toronto, Canada \\ E. Karampinos Lassonde Institute of Mining, University of Toronto, Canada \\ P. Turcotte Agnico-Eagle Mines Ltd., Canada \\ F. Mercier-Langevin Agnico-Eagle Mines Ltd., Canada
}

\begin{abstract}
In several deep and high stress mines, squeezing rock conditions are caused by the presence of foliation and the orientation of the drift with respect to this foliation. This paper relies on field observations from two hard rock mines to support the hypothesis that the angle of the drift walls, with respect to the orientation of the foliation, has a significant influence on the level of squeezing. This study evolved by recognising that, irrespective of the employed support system, it was difficult to maintain open drifts developed subparallel with respect to foliation. This had a direct impact on the required rehabilitation to keep the drifts functional. A database was constructed at the Lapa and LaRonde mines of Agnico-Eagle, recording the observed levels of squeezing for drifts developed at varying angles with regard to foliation.
\end{abstract}

\section{Introduction}

A large number of underground hard rock mines are exposed to large scale deformation often referred to as squeezing ground conditions. This has major economic and safety implications for the mining industry, especially where deeper excavations are developed. In a mining context the Squeezing Task Force, Potvin and Hadjigeorgiou (2008), suggested that "squeezing ground conditions are encountered when the total displacement of an excavation or, more specifically, the drive closure, will reach at least tens of centimetres within the life expectancy of a supported drive. In general, mine drives are designed to be in operation up to 18 months to two years. It is also implied that in squeezing ground the resulting loads will be greater than the capacity of a 'stiff' support system. This often results in significant failure of ground support and necessitates extensive rehabilitation work."

In deep and high stress mines, squeezing conditions are caused by the presence of foliation and the orientation of the drift with respect to this foliation. This is supported by analytical buckling solutions, Kazakidis (2002), physical modelling, Lin et al. (1984) and by numerical studies, Beer et al. (1981) and Hsu et al. (2004). Although many hard rock mines around the world have problems associated with large scale deformations, there are only few documented case studies in mining under squeezing rock conditions (Struthers et al., 2000; Beck and Sandy, 2003; Potvin and Slade; 2007, Sandy et al., 2010; Mercier-Langevin and Hadjigeorgiou, 2011; Vakili et al., 2012).

Ground support strategies used to control large deformations in Australia and Canada have been reviewed by Potvin and Hadjigeorgiou (2008). It was suggested that an effective ground support system for squeezing ground employs both reinforcement elements and surface support units. Reinforcement elements maintain the self-supporting capacity of the rock mass surrounding the excavation by keeping together the reinforced rock mass unit around each tendon and mitigate the rate of convergence of a drift. Surface support is required to deform in order to accommodate the resulting high deformations while maintaining the integrity of the reinforced rock unit.

In a mining context it was suggested that squeezing ground conditions display strain approximately greater than $2 \%$. High deformations are generally related to the presence of a prominent structural failure such as a 
dominant fracture set, intense foliation or a shear zone and high stress (Potvin and Hadjigeorgiou, 2008). In addition, the host rock type, where squeezing was most dominant, was characterised by relatively weak intact rock strength (less than $60 \mathrm{MPa}$ ).

Mercier-Langevin and Hadjigeorgiou (2011) reported on the development of a 'Hard Rock Squeezing Index' for underground mines based on case studies conducted in various mining operations and calibrated based on in situ observations at the LaRonde mine in Quebec, Canada. This index was intended as a preliminary indicator of the squeezing potential of a rock mass and can be potentially useful at other hard rock mines experiencing squeezing ground conditions.

\section{$2 \quad$ Mine sites}

Squeezing conditions are investigated in two underground Canadian mines owned by Agnico-Eagle Mines Ltd: LaRonde and Lapa. Both mines are located in the Abitibi region of Northwest Quebec and have to manage large rock mass deformations that require rehabilitation of affected drifts. Of interest is that the two mines, located $11 \mathrm{~km}$ from each other, provide a spectrum of squeezing ground control conditions.

The LaRonde orebody is a world-class Au-Ag-Cu-Zn massive sulphide lenses complex with reserves extending from surface down to $3,110 \mathrm{~m}$ and still open at depth. The mine has been in operation since 1988. Two mining methods are used - longitudinal retreat with cemented backfill, and transverse open stoping with cemented and unconsolidated backfill. Current production is below $940 \mathrm{~m}$ depth using a $2,240 \mathrm{~m}$ deep shaft. After the construction of an $832 \mathrm{~m}$ long internal shaft, new development is in progress to establish a new production horizon in the deepest part of mine $(2,930 \mathrm{~m})$. Over $14 \mathrm{~km}$ of lateral development has been planned in 2013 to achieve the mining plan in variable ground conditions. As the operating depth and the stress to strength ratio increased, the behaviour of the rock mass changes has changed from hard and brittle to soft and squeezing. In some areas of the mine, the total wall convergence can be in excess of one meter with resulting fracturing extending up to six meters into the rock mass.

Lapa is a high grade gold mine that began production in 2009 through a 1,369 $\mathrm{m}$ deep shaft using two mining methods - longitudinal retreat with cemented backfill, and locally transverse open stoping with cemented backfill. The mine has reported squeezing conditions and efforts were made to investigate the type of squeezing mechanism and support strategy to control large deformations (Mercier-Langevin and Wilson, 2013).

\subsection{Ground support}

In comparing Australian and Canadian ground support practices in squeezing ground conditions it was noted that the choice of surface support was different, Potvin and Hadjigeorgiou (2008). It was also observed that Australian mines rely considerably on the use of fibrecrete while Canadian mines rely on the use of welded screen, sometimes complemented with mesh straps. The use of in-cycle fibre reinforced shotcrete was justified by operators as it can retard rock mass degradation and control large deformations. Using a thick layer of shotcrete results in a support that is too stiff for squeezing ground, often requiring a further layer of screen. This creates a composite liner that is initially stiff followed by a ductile behaviour after the fibrecrete has cracked. The choice of reinforcement elements also varies from operation to operation without any clear consensus.

LaRonde had reported some success in controlling closure using friction bolts. However, their capacity in shear loading is limited. Friction bolts 'lock up' when buckling of foliation reaches a certain level but they fail, usually at the collar of the bolt, when further deformation occurs. Limited success was also reported with the use of cement grouted cable bolts, yielding cable bolts and modified cone bolts in squeezing ground. Some success has been achieved using a hybrid bolt (Mercier-Langevin and Turcotte, 2007). The preference for the hybrid bolts has been justified by reduction in the rehabilitation requirements as compared to other systems. The current standard for LaRonde calls for screen brought to $0.6 \mathrm{~m}$ from the ground, friction sets in the sidewalls and rebar in the back. This is complemented by the use of hybrid bolts 
and straps in the side walls Figure 1. The hybrid bolts are installed at an offset height on the south wall in order to account for the expected deformation associated with the foliation.
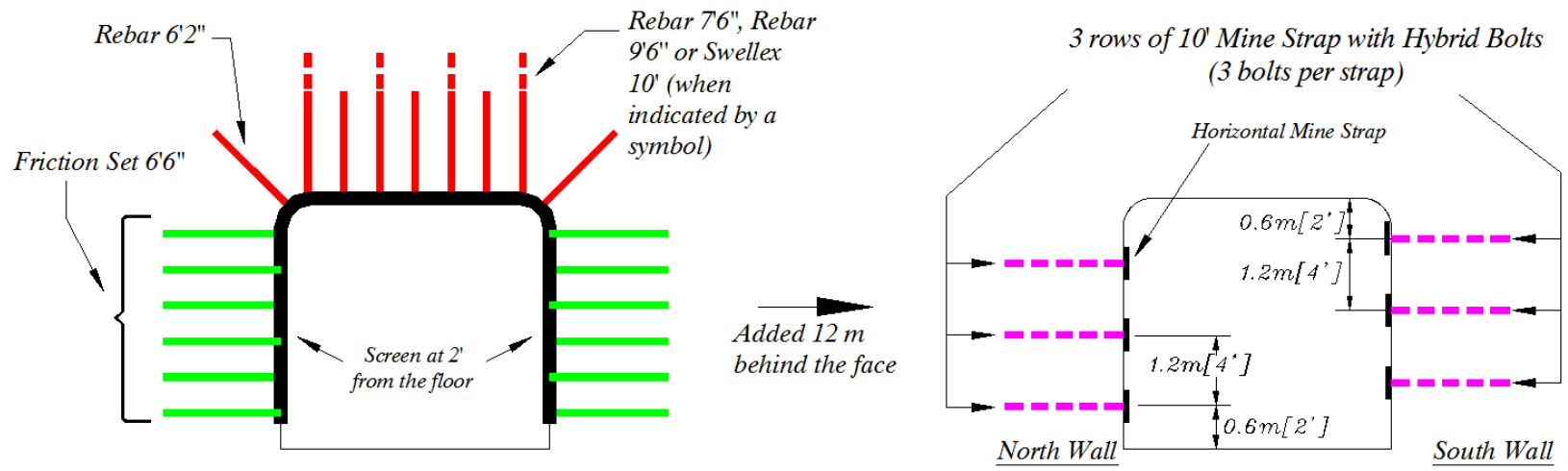

Figure 1 Ground support standards for squeezing rock conditions at LaRonde

Ground support at Lapa was inspired by the success of the hybrid bolt at LaRonde. The mine employs three standards for areas where squeezing occurs. Longer support is used in the walls, and split set bolts are upgraded to higher capacity hybrid bolts in the very weak schist zones (ultramafic) wall(s) susceptible to squeezing (Figure 2). In all ground support standards, screen (\#6 gauge, $4.1 \mathrm{~mm}$ diameter) is brought within $0.6 \mathrm{~m}$ from the floor to prevent unravelling of the lower part of the sidewalls.

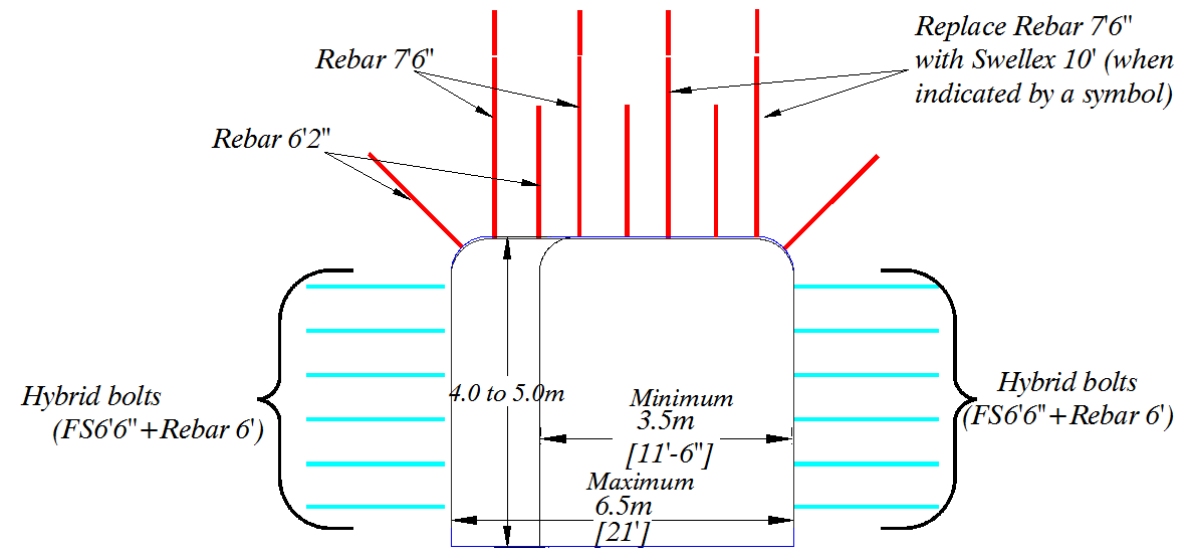

Figure 2 Ground support standards for squeezing rock conditions at Lapa: hybrid bolts are installed in both north and south walls in the presence of ultramafic rock

The support system incorporating screen and the hybrid bolt evolved based on the advantages of the hybrid bolt, particularly that it could be easily installed in highly fractured ground. Other considerations were the high capacity of the bolt head and steel bar (approximately 15 tonnes) that prevented early failure. Early trials at LaRonde demonstrated that it was successful where friction bolts failed (Figure 3).

It has been demonstrated that the introduction of the hybrid bolt in the support system resulted in a significant reduction since 2006 in 'purging 'of drifts that display excessive squeezing (Figure 4). When convergence reaches a point where wall stability is compromised or if equipment clearance is insufficient, an 8 yard scoop-tram is used to 'purge' the walls, i.e. to remove excess material. This is a critical operation and is always performed under close supervision from ground control personnel. As it is difficult to control the amount of broken material that falls off during purging, the final size of the drift often exceeds its original dimensions. It is then necessary to install secondary back support, such as cable bolts, in order to stabilise the greater spans created by scaling of the side walls. This rehabilitation process is costly and timeconsuming and only used as a last resort. Another benefit was increased equipment availability for priority development headings. 


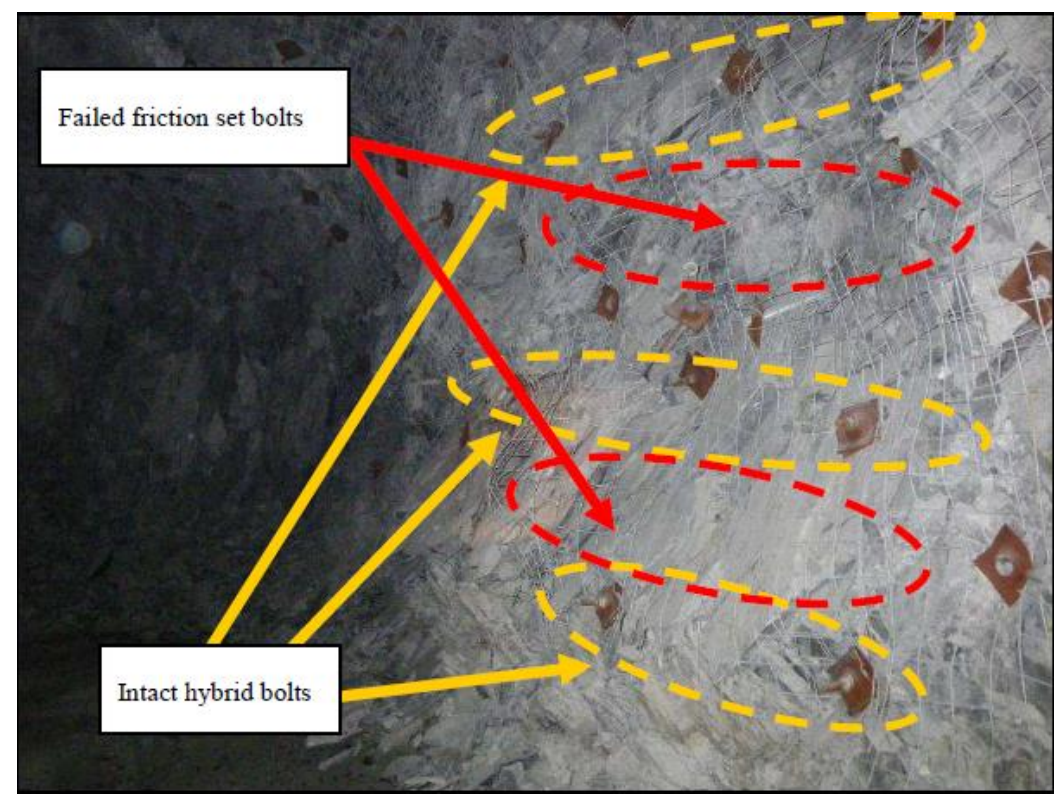

Figure 3 Relative success of the hybrid bolt as compared to friction bolts for squeezing rock conditions at LaRonde, after Turcotte (2010)

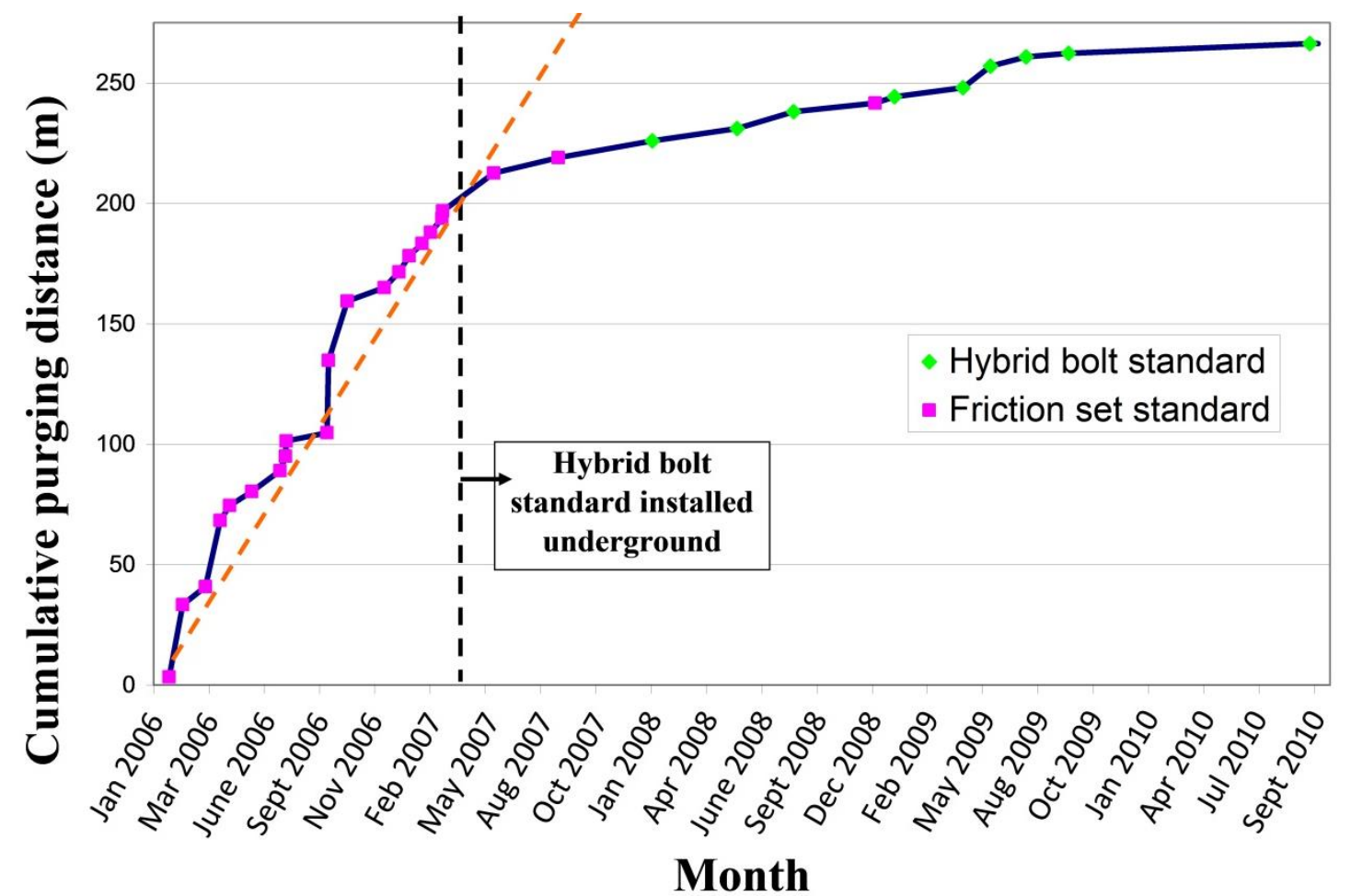

Figure 4 Reduction in cumulative distance purged under the 215 Level as related to the introduction of the hybrid bolt as part of the ground support standard for squeezing rock conditions at LaRonde (after Turcotte, 2010)

\section{$3 \quad$ Mitigating the degree of squeezing}

Mining experience has shown that it is not a realistic option to stop deformation in squeezing ground. It has been demonstrated that such an approach results in frequent rehabilitation and high support costs. This resulted in most mines pursuing a modified support strategy whereby the objective becomes one of controlling rather than arresting the degree of drive closure squeezing. To better understand how to 
manage this deformation it is necessary to investigate the different parameters that control the squeezing process.

At the LaRonde mine it was recognised that there was a potential advantage of modifying the drift orientation with respect to in situ foliation (Mercier-Langevin and Turcotte, 2007). Driving haulage drifts at a favourable angle with respect to foliation resulted in increased development per level. The cost of the reconditioning work and associated production delays was significantly reduced.

\subsection{Influence of drift orientation}

This was quantified by the angle of interception $(\psi)$ which was defined as the angle between the normal to the foliation planes and the normal to the wall of interest (Figure 5). The influence of the angle of interception was evident at 2,150 m depth. As shown in Figure 6, there was little evidence of squeezing when the foliation was perpendicular to the drift orientation, relatively more severe at $45^{\circ}$ and extreme when foliation was parallel to the drift.

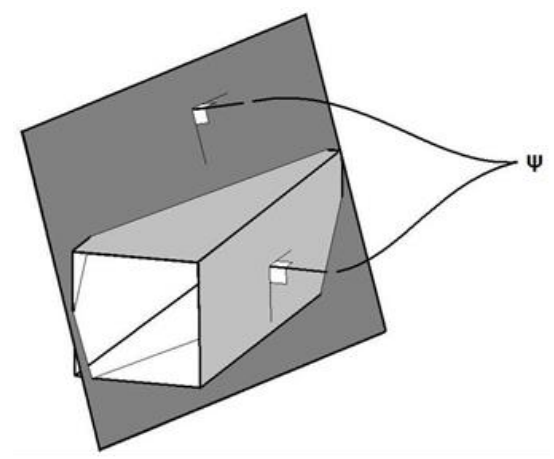

Figure 5 Definition of angle of interception $(\psi)$, after Mercier-Langevin and Hadjigeorgiou (2011)

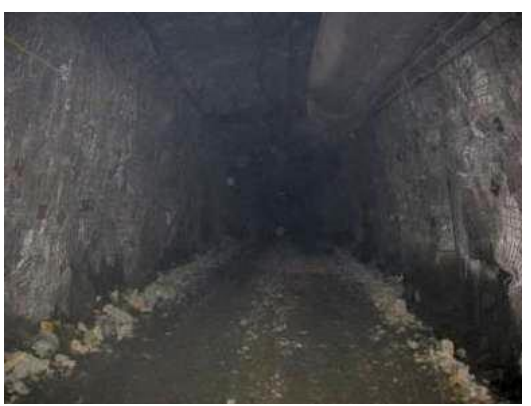

a)

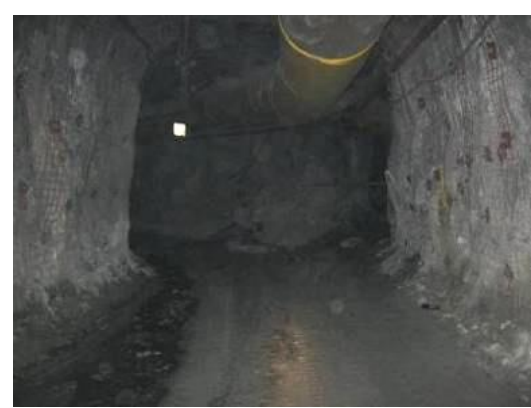

b)

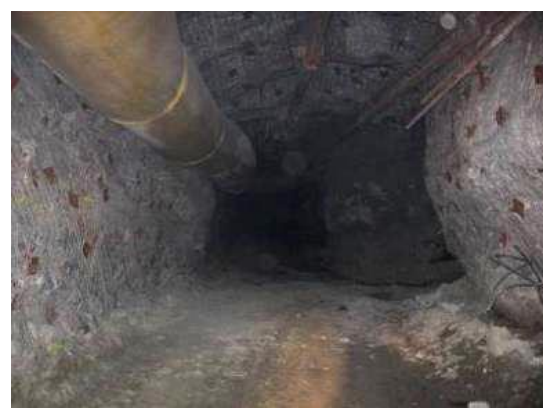

c)

Figure 6 Variations in squeezing severity in three locations less than $100 \mathrm{~m}$ apart at 2,150 m depth, after Mercier-Langevin and Hadjigeorgiou (2011); a) perpendicular - no squeezing; b) 45 degrees - minor or no squeezing; c) parallel - severe squeezing

This had significant ramifications on the performance of the ground support systems employed at the LaRonde Mine. A first approach to quantify the impact of drift orientation was made by Mercier-Langevin (2005). Based on 23 field observations in drifts at the LaRonde mine the degree of squeezing was defined based the observed level of damage to the support, the angle of interception between the foliation and the effect of stress on the resulting excavation convergence. In drifts developed sub-parallel with respect to foliation, it was recognised that irrespective of the employed support system it was difficult to maintain the drifts open and it was necessary to resort to regular rehabilitation to keep the drifts functional (Mercier-Langevin and Hadjigeorgiou, 2011). Drifts developed at varying angles with regards to foliation, displayed different levels of squeezing. This orientation phenomenon is supported by a mechanistic analysis. Auto confinement of foliation planes is greater when the angle between the normal to the free 
face and the normal to the foliation increases. It is recognised that even a small confinement is sufficient to inhibit buckling failure of the slabs. Kazakidis (2002) demonstrated that a relatively low confining pressure could be sufficient to prevent buckling failure of bedding planes.

\subsection{Updated database investigating the influence of drift orientation}

The original database was extended from case studies at both LaRonde and Lapa Mines, 41 case studies from LaRonde and 22 case studies from Lapa. The following parameters were recorded: the angle of interception $(\psi)$; the dip angle of the foliation; the observed damage; the development date; the stress effect due to mining activity; the support system used; the additional support installed and the presence of water. Any rehabilitation or purging was recorded. Some of the drifts were surveyed using the cavity monitoring survey (CMS) instrument CMS V400 (Optech Incorporated, 2010). In drifts where a CMS survey was not available, a laser distance measurer was used to measure the distance between the two sidewalls at 1.5 and $2.5 \mathrm{~m}$ height, as shown in Figure 7. A 3D survey of each drift is available at the mine. This is produced by surveying one point at the back, the floor and each sidewall.

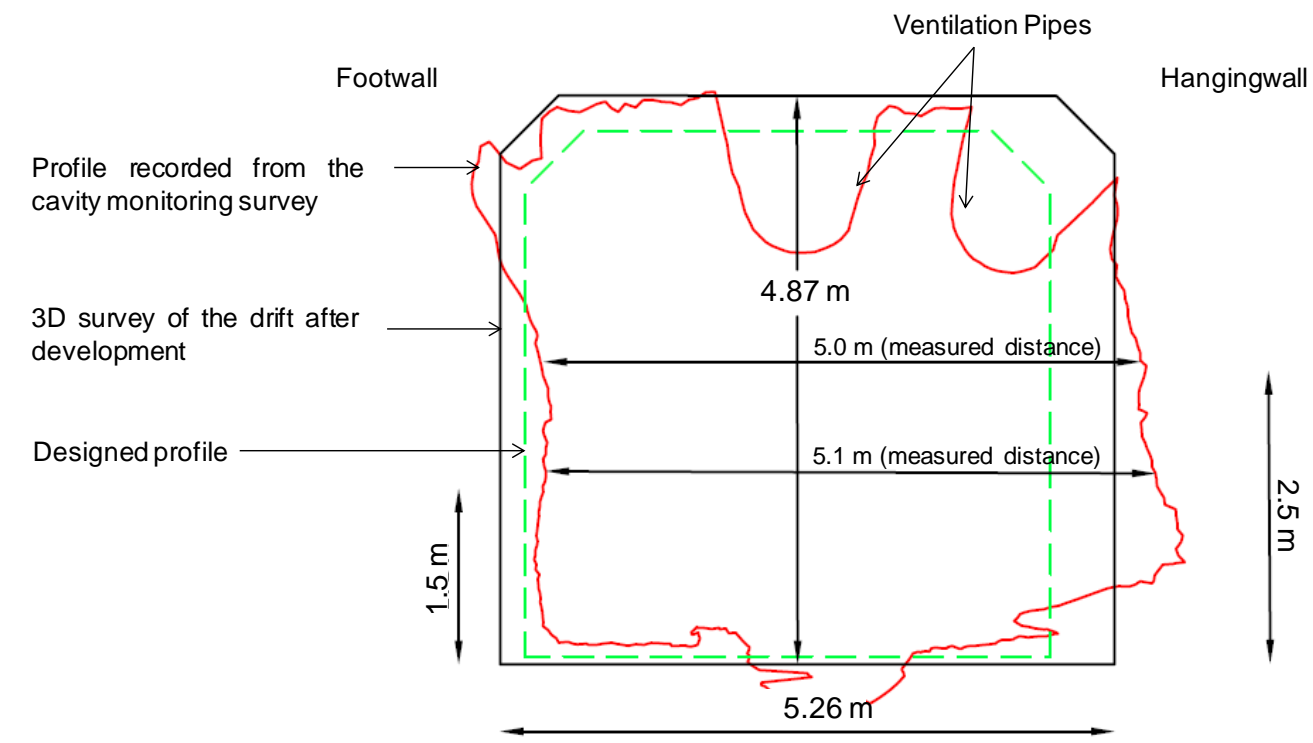

Figure 7 Determination of sidewall convergence

\subsection{Quantifying observed convergence}

In earlier work at the mine the observed convergence was recorded in a qualitative way. In recent work this has been supplanted by quantitative records. The total sidewall convergence $(\delta)$ is defined as the difference between the lowest measured sidewall distance and the surveyed width (L). The total sidewall convergence was expressed as \% strain $(\varepsilon)$ :

$$
\varepsilon=\frac{\delta}{L} * 100
$$

There are practical considerations in interpreting these field data. For example it is noted that if a drift closes to near $3.5 \mathrm{~m}$ it is purged as the convergence renders its non-operational for equipment. Consequently a value of $3.5 \mathrm{~m}$ was used as the lowest distance measured. Although the data collection is still in progress a working classification for squeezing in a hard rock mining environment has been proposed:

- No or low squeezing $(0 \%<\varepsilon<5 \%)$.

- Moderate squeezing $(5 \%<\varepsilon<10 \%)$.

- Pronounced squeezing or rehabilitated drifts $(10 \%<\varepsilon<35 \%)$. 
- Extreme squeezing $(35 \%<\varepsilon)$.

These strain ranges differ from other published work in civil engineering tunnelling applications summarised by Potvin and Hadjigeorgiou (2008). The reason for this is a higher tolerance for rock mass failure (and its associated rehabilitation) that is accepted by mining operators. Figure 8 provides examples of squeezing observed at both Lapa and LaRonde mines. 


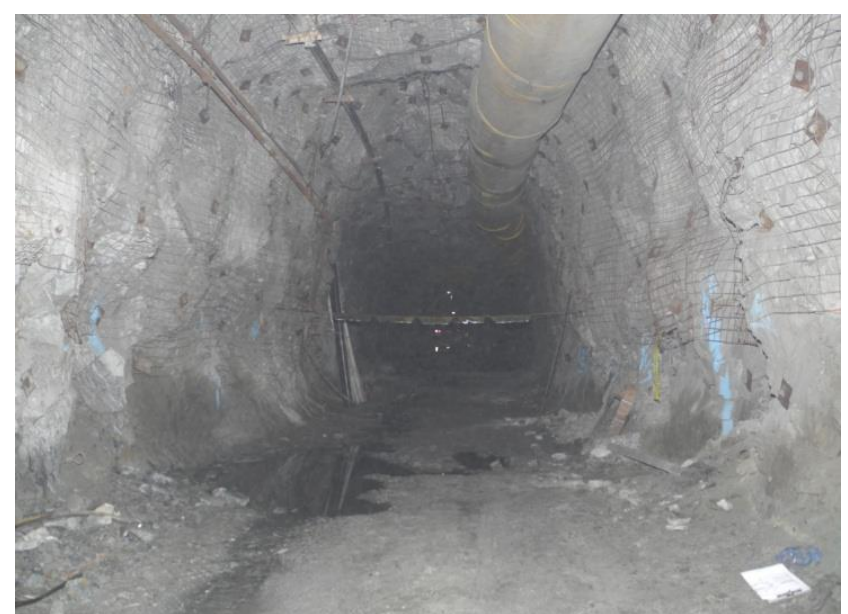

\section{No squeezing}

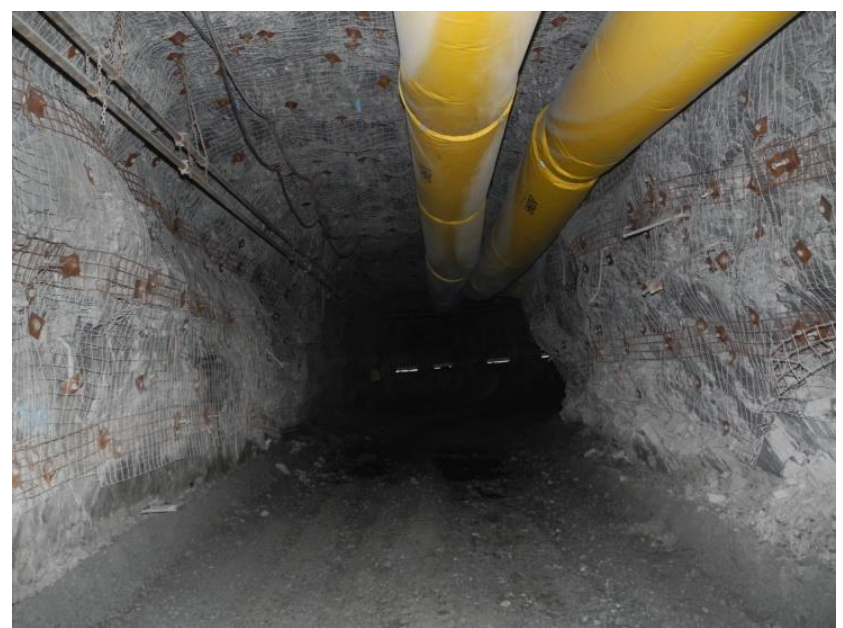

Moderate squeezing; convergence

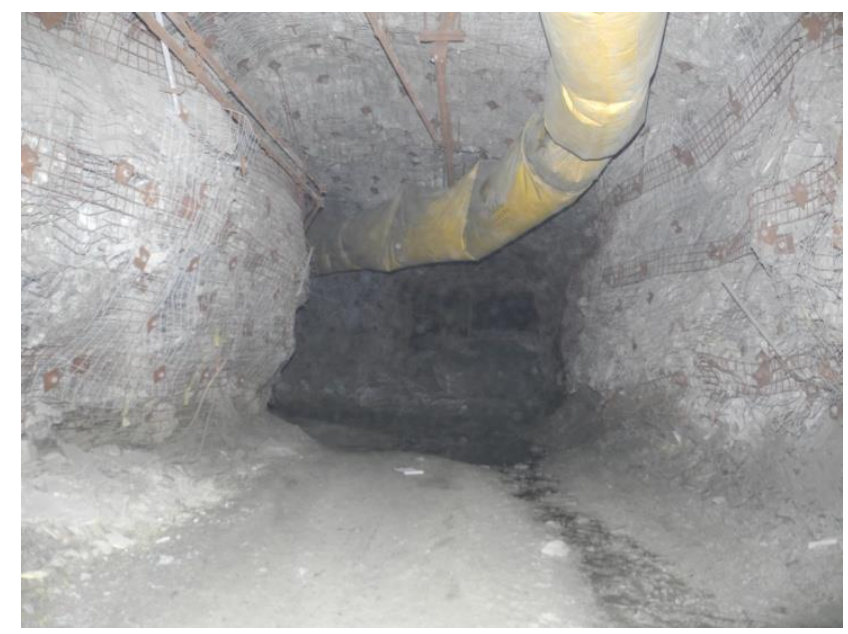

Rehabilitated drift

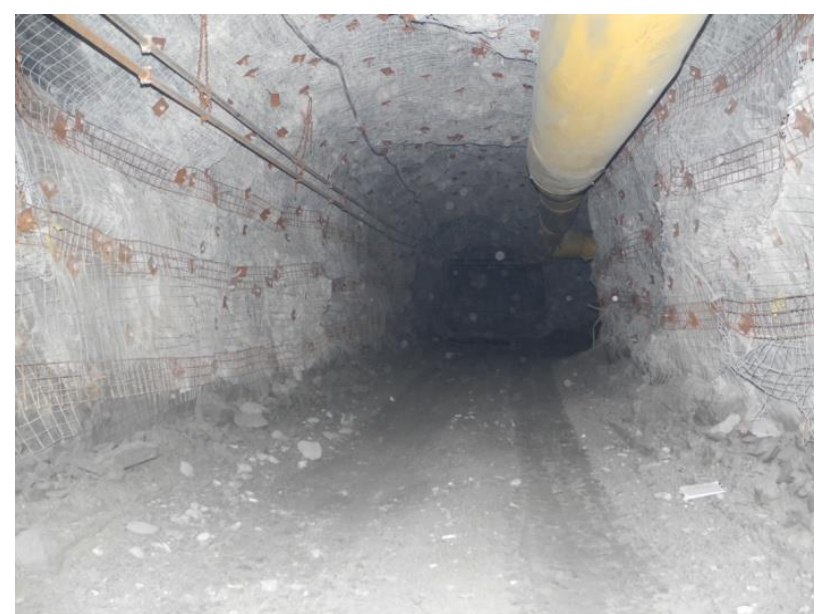

Low squeezing; bolts take load

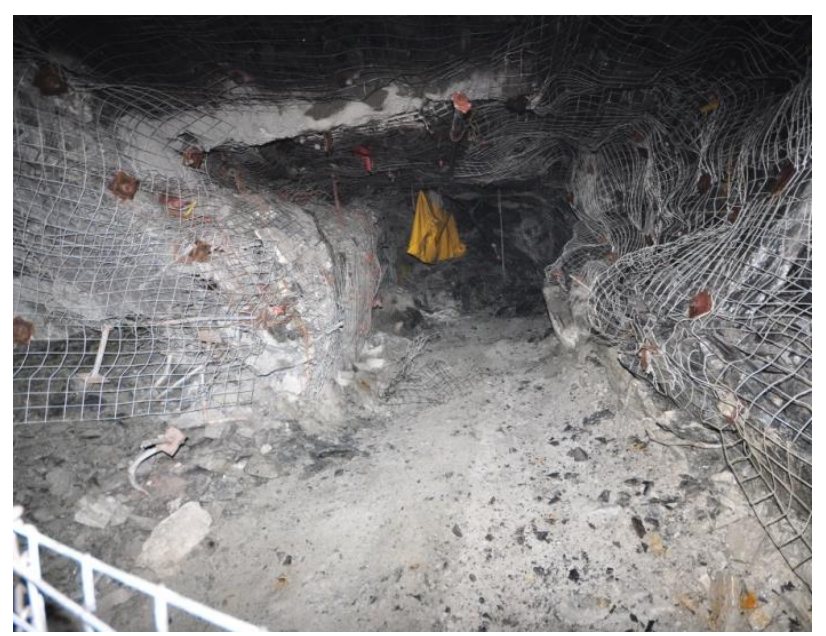

\section{Extreme squeezing}

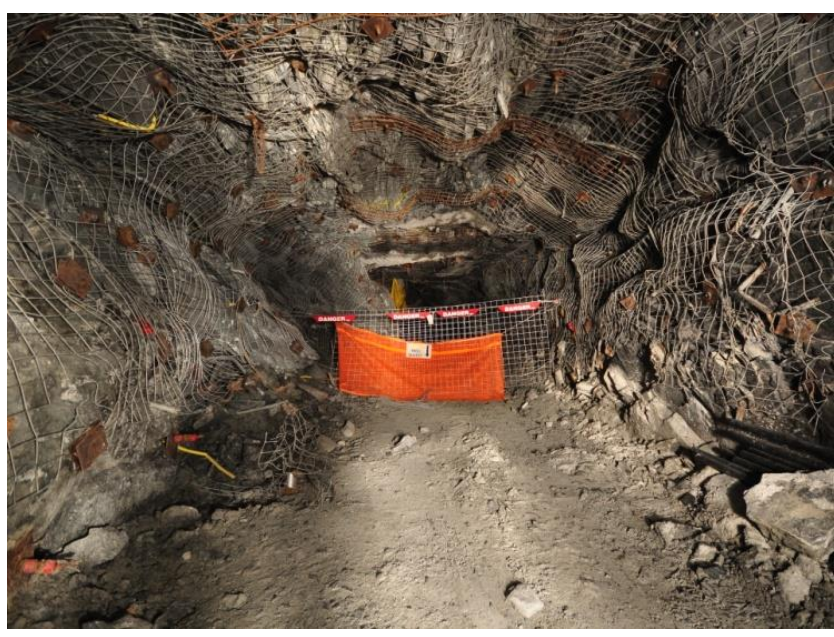

Purged drift

Figure 8 Examples of drifts subjected to squeezing at the LaRonde and Lapa mines

The influence of angle of interception $(\psi)$ on resulting sidewall strain at the LaRonde and Lapa mines is illustrated in Figure 9. This diagram captures only part of the salient behaviour in that the data are 
controlled by the time that the readings were made and that there are operational constraints that do not allow for a drift to close to a width smaller than $3.5 \mathrm{~m}$. Nevertheless, there are definite indications that increasing the drift angle of interception with respect to foliation will invariably reduce the degree of squeezing. In the absence of a ground support system that can control pronounced and extreme squeezing in a mining context these results make a strong case for exploring changes in the orientation development. This has been an opportunity at LaRonde, while it has been more challenging at Lapa. The reason is the mining method at Lapa that allows less flexibility.

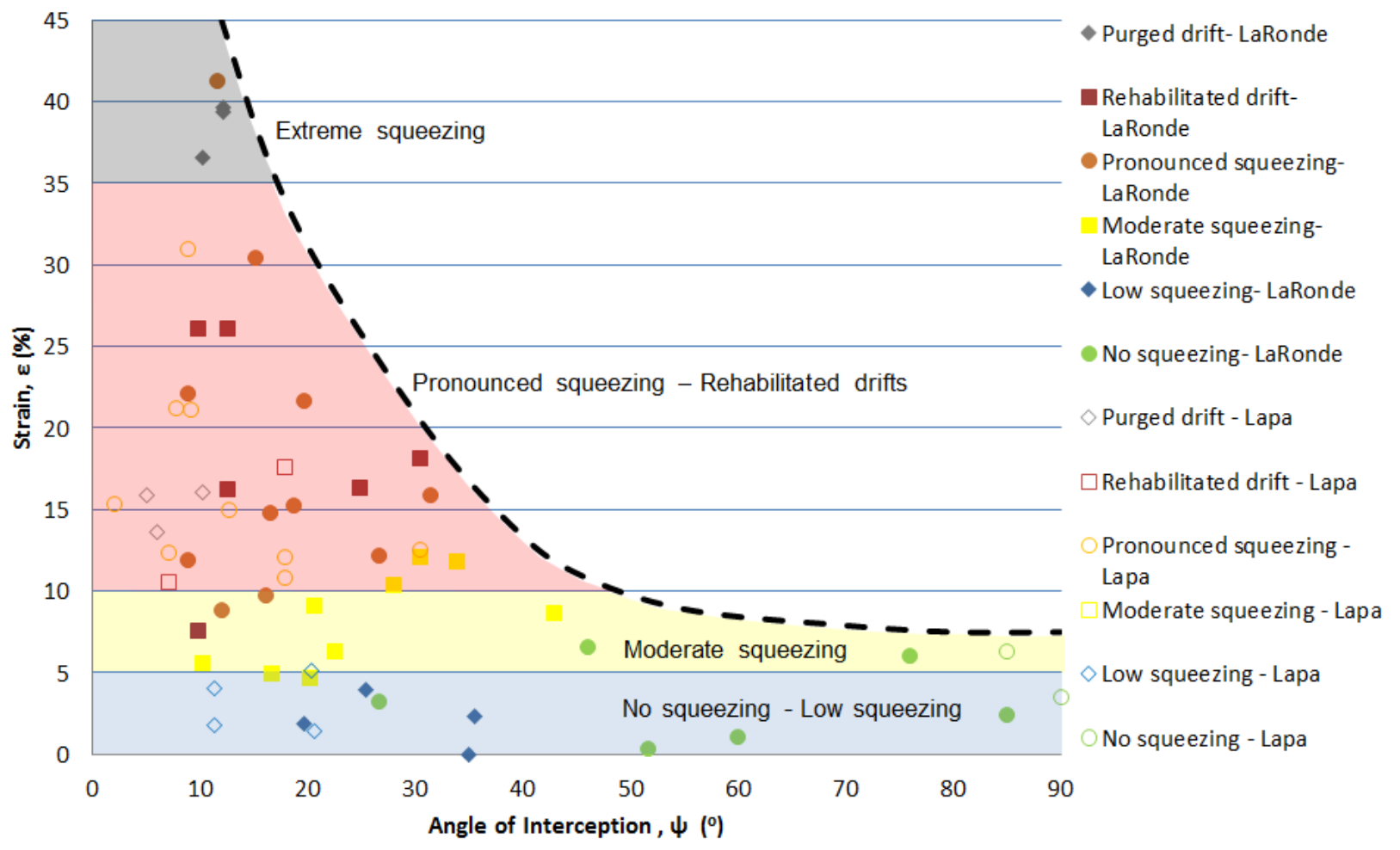

Figure 9 Influence of angle of interception $(\psi)$ on resulting sidewall strain at the LaRonde and Lapa mines

Given the limitations of the results shown in Figure 9, it is suggested that there is a need to better define and capture the transition between the various squeezing zones. This can potentially be achieved by complementing field observations with parametric numerical studies.

\section{$4 \quad$ Conclusions}

In a mining environment, the threshold of what is considered acceptable squeezing is significantly higher than in civil engineering tunnelling operations. This allows more flexibility to operators. On the other hand, mines have to work with what are considerably higher constraints in the choice of economic support. Squeezing ground conditions in mines are characterised by significant failure of ground support systems that often necessitates considerable rehabilitation work.

The LaRonde and Lapa mines are employing similar support strategies aiming in managing squeezing ground conditions as opposed to stopping deformation, which is not a realistic option in a mining context. This paper summarises on-going work on quantifying the influence of the angle of interception between the drift and the inherent foliation. Selecting an appropriate angle of interception can result in a more manageable squeezing level which can arguably increase the performance of a suitable support system for squeezing rock conditions. This, however, may not always be a practical option in a mining operation. This work also contributes to the fine tuning, validation and extension of the Squeezing Index that has been proposed by Mercier-Langevin and Hadjigeorgiou (2011). 


\section{Acknowledgement}

The authors acknowledge the support of Agnico-Eagle Mines, Division LaRonde and Lapa and the Natural Science and Engineering Research Council of Canada.

\section{References}

Beck, D.A. and Sandy, M.P. (2003) Mine Sequencing for High Recovery in Western Australian Mines, in Proceedings Twelfth International Symposium on Mine Planning and Equipment Selection, 23-25 April 2003, Kalgoorlie, Australia, CD-Rom.

Beer, G., Meek, J.L. and Cowling, R. (1981) Prediction of behaviour of shale hangingwalls in deep underground excavations, in Proceedings Fifth I.S.R.M. Symposium, 1981, Melbourne, Australia, Balkema, Rotterdam, p. D45-1.

Hsu, S.C., Chiang, S.S. and Lai, J.R. (2004) Failure mechanisms of tunnels in weak rock with interbedded structures, Paper $2 B 34-$ SINOROCK2004 Symposium, International Journal of Rock Mechanics and Mining Sciences, Vol. 41, No. 3, f.

Kazakidis, V.N. (2002) Confinement Effects and Energy Balance Analyses for Buckling Failure Under Eccentric Loading Conditions, Rock Mechanics and Rock Engineering, Vol. 35 (2), pp. 115-126.

Lin, Y., Hong, Y., Zheng, S. and Zhang, Y. (1984) Failure modes of openings in a steeply bedded rock mass, Rock Mech, Rock Eng., Vol. 17, pp. 113-119.

Mercier-Langevin, F. and Wilson, D. (2013) Lapa mine - ground control practices in extreme squeezing ground, in Proceedings Seventh International Symposium on Ground Support in Mining and Underground Construction, B. Brady and Y. Potvin (eds), 13-15 May 2013, Perth, Australia, Australian Centre for Geomechanics, Perth, pp. 119-132.

Mercier-Langevin, F. and Hadjigeorgiou, J. (2011) Towards a better understanding of squeezing potential in hard rock mines, AusIMM, Mining Technology, 2011, Vol. 120, No. 1, pp. 36-44.

Mercier-Langevin, F. and Turcotte, P. (2007) Expansion at Depth at Agnico-Eagle's LaRonde Division - Meeting Geotechnical Challenges without Compromising Production Objectives, in Challenges in Deep and High Stress Mining, Y. Potvin, J. Hadjigeorgiou and D. Stacey (eds), Australian Centre for Geomechanics, Perth, pp. 189-195.

Mercier-Langevin, F. (2005) Projet de convergence des galeries - Phase 1: Consolidation de l'information disponible à la mine, Internal Memo, Agnico-Eagle Mines Ltd - LaRonde Division, Cadillac, Canada, 13 p.

Optech Incorporated (2010) CMS V400 Operation Manual, Cavity Monitoring System, Ontario, Canada.

Potvin, Y. and Hadjigeorgiou, J. (2008) Ground Support Strategies to Control Large Deformations in Mining Excavations, The Journal of the Southern African Institute of Mining and Metallurgy, Vol. 108 July 2008, pp. 393-400.

Potvin, Y. and Slade, N. (2007) Controlling extreme ground deformation; Learning from four Australian case studies, in Challenges in Deep and High Stress Mining, Y. Potvin, J. Hadjigeorgiou and D. Stacey (eds), Australian Centre for Geomechanics, Perth, pp. 355-361.

Sandy, M., Sharrock, G., Albrecht, J. and Vakili, A. (2010) Managing the Transition from Low Stress to High Stress Conditions, in Proceedings Second Australasian ground Control in Mining Conference, 23-24 November 2010, Sydney, Australia, AusIMM, Carlton, pp. 1-8.

Struthers, M.A., Turner, M.H., McNabb, K. and Jenkins, P.A. (2000) Rock Mechanics Design and Practice for Squeezing Ground and High Stress Conditions at Perseverance Mine, in Proceedings MassMin 2000, G. Chitombo (ed), 29 October to 2 November 2000, Brisbane, Australia, Australasian Institute of Mining and Metallurgy, Melbourne, pp. 755-764.

Turcotte, P. (2010) Field Behaviour of Hybrid bolt at LaRonde Mine, in Proceedings Fifth International Seminar on Deep and High Stress Mining (Deep Mining 2010), M. Van Sint Jan and Y. Potvin (eds), 6-8 October 2010, Santiago, Chile, Australian Centre for Geomechanics, Perth, pp. 309-319.

Vakili, A., Sandy, M. and Albrecht, J. (2012) Interpretation of Non-linear Numerical Models in Geomechanics-A case study in the Application of Numerical Modelling for Raise Bored Shaft Design in a Highly Stressed and Foliated Rock Mass, in Proceedings MassMin 2012, 10-14 June 2012, Sudbury, Canada, Canadian Institute of Mining, Metallurgy and Petroleum, Westmount, CD-rom. 
Squeezing ground 